UCRL-JC-127366

Preprint

\title{
Alternative Poloidal Field Configurations for ITER
}

\author{
R.H. Bulmer and G.H. Neilson
}

This paper was prepared for submittal to

17th IEEE/NPSS Symposium on Fusion Engineering (SOFE '97)

October 6-10, 1997

San Diego, CA

September 2, 1997

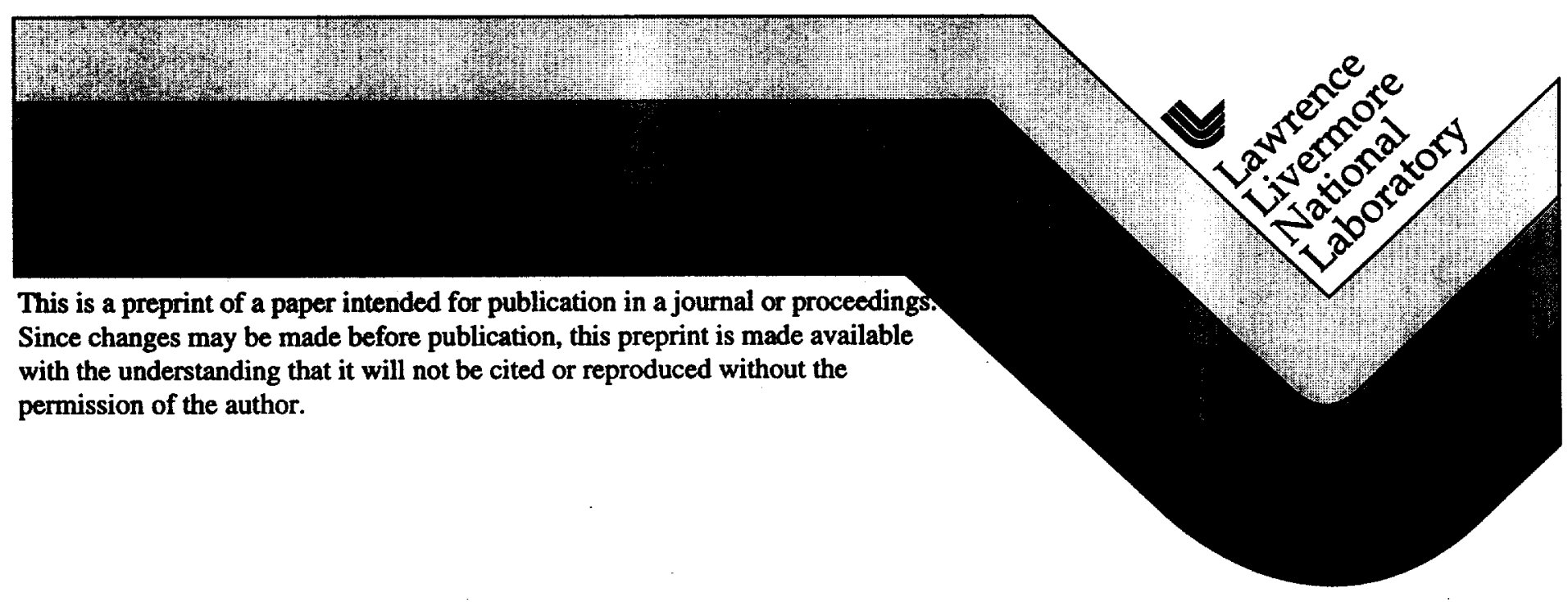




\section{DISCLAIMER}

This document was prepared as an account of work sponsored by an agency of the United States Government. Neither the United States Government nor the University of California nor any of their employees, makes any warranty, express or implied, or assumes any legal liability or responsibility for the accuracy, completencess, or usefulness of any information, apparatus, product, or process dieclosed, or represents that its use would not infringe privately owned righs. Reference herein to any specific commercial product, process, or service by trade name, trademark, manufacturer, or otherwise, does not necessarily constitute or imply its endorsement, recommendation, or favoring by the United States Government or the University of California. The views and opinions of authors expressed herein do not necessarily state or refiect those of the United States Government or the University of California, and shall not be used for advertising or product endorsement purposes. 


\title{
Alternative Poloidal Field Configurations for ITER*
}

\author{
R. H. Bulmer' and G. H. Neilson ${ }^{b}$ \\ "Lawrence Livermore National Laboratory, University of California, Livermore, CA 94550 \\ 'Princeton Plasma Physics Laboratory, Princeton, NJ 08543
}

\begin{abstract}
The US Home Team has investigated the physics and engineering issues for two alternate poloidal field coil configurations for ITER. The first is called the Segmented CS configuration, where all of the solenoid modules are pancakewound. The second option, termed the Hybrid CS configuration, utilizes a layer-wound central module and pancake-wound end modules. Performance comparisons are presented for the baseline design and the two alternate $P F$ configurations, characterizing the $21 \mathrm{MA}$ reference scenario. Alternate operating modes such as reverse-shear operation and a $17 \mathrm{MA}$ driven mode were evaluated, but are not reported here.
\end{abstract}

\section{INTRODUCTION}

The baseline configuration of the poloidal field (PF) coils for ITER features a $12 \mathrm{~m}$ long monolithic central solenoid, which is layer-wound and consists of three regions of varying superconductor grades. The stray field from the ends of this long coil inhibit plasma shaping flexibility and shape conformity of the plasma over the reference $21 \mathrm{MA}$ ignited scenario. The plasma performance can be improved by vertically segmenting the solenoid. The Segmented CS configuration offers superior plasma performance but suffers from the necessity to invoke high field $(-13 \mathrm{~T})$ joints in the superconductor. Development of such high field joints is beyond the scope of the ITER Engineering Design Activity, and therefore this concept was abandoned. The difficulties of the Segmented CS design prompted the US Home Team to develop a Hybrid CS option, where the central portion of the solenoid is of the same design as the baseline design-only shorter. In this configuration, independently controlled end-coils are located beyond the central module (separated by vertical gaps of about $1.5 \mathrm{~m}$ ) to allow space for the leads of the $9.5 \mathrm{~m}$ layer-wound central module. The Hybrid CS design suffers from excessive insulation bond stress but it is thought that a modest R\&D effort can resolve this problem.

This paper addresses the performance of the baseline design and the two alternate concepts. Plasma control and power supply issues are addressed in [1], and the engineering aspects of the Hybrid CS design are presented in [2]. Details are available in the report of the US Home Team [3].

\section{PF COIL CONFIGURÄTIONS}

\section{A. Detailed Design Configuration-the Baseline}

Fig. 1 shows the PF configuration for the ITER Detailed Design Report [4], developed during 1996. The $12 \mathrm{~m}$ long CS coil is radially graded into three regions, a cost effective arrangement which also enhances poloidal flux production. The $\mathrm{CS}$ and two of the shaping coils (PF2 and PF7) require $\mathrm{Nb}_{3} \mathrm{Sn}$ superconductor because of the high field levels. The other shaping coils are designed with NbTi superconductor. Coil specifications (current centroid, cross section, current capacity and conductor type) are listed in Table I.

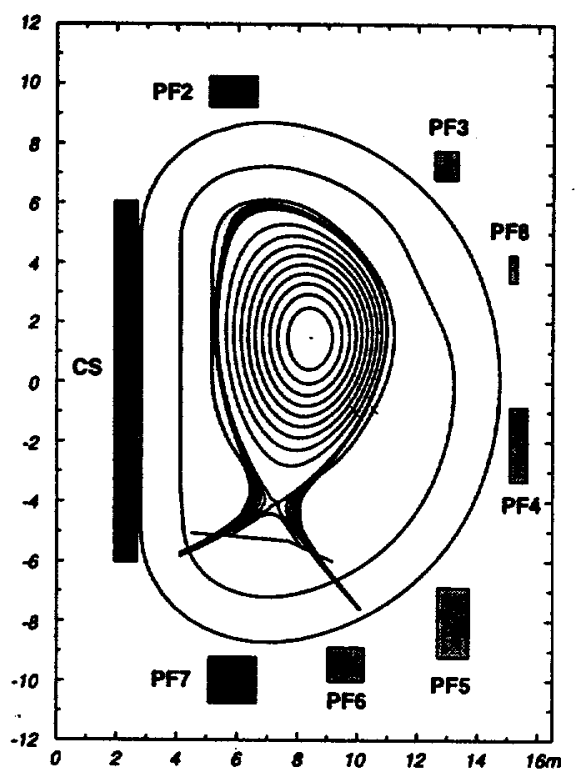

Fig. 1. PF coil arrangement for the Detailed Design Report.

\begin{tabular}{|c|c|c|c|c|c|c|}
\hline $\begin{array}{c}\text { coil } \\
\text { name }\end{array}$ & $\begin{array}{c}\boldsymbol{R}_{\mathrm{s}} \\
\mathbf{m i n}\end{array}$ & $\underset{m m}{Z_{m}}$ & $\begin{array}{l}\Delta R_{c} \\
\text { mm }\end{array}$ & $\underset{\mathrm{mm}}{\Delta Z_{\mathrm{m}}}$ & $\begin{array}{l}N I_{\text {cap }} \\
\text { MAt }\end{array}$ & $\begin{array}{l}\text { cond. } \\
\text { type }\end{array}$ \\
\hline $\begin{array}{l}\text { CS } \\
\text { PF2 } \\
\text { PF3 } \\
\text { PF4 } \\
\text { PF5 } \\
\text { PF6 } \\
\text { PF7 } \\
\text { PF8 }\end{array}$ & $\begin{array}{r}2305 \\
5859 \\
12947 \\
15364 \\
13198 \\
9638 \\
5859 \\
15177\end{array}$ & $\begin{array}{r}0 \\
9738 \\
7277 \\
-2090 \\
-8043 \\
-9452 \\
-9981 \\
3809\end{array}$ & $\begin{array}{r}747 \\
1554 \\
766 \\
593 \\
1046 \\
1180 \\
1580 \\
273\end{array}$ & $\begin{array}{r}12073 \\
1042 \\
963 \\
2485 \\
2334 \\
1135 \\
1553 \\
915\end{array}$ & $\begin{array}{r}140.9 \\
18.5 \\
99.4 \\
17.6 \\
19.2 \\
12.7 \\
27.3 \\
3.5\end{array}$ & $\begin{array}{c}\mathrm{Nb}_{3} \mathrm{Sn} \\
\mathrm{Nb}_{3} \mathrm{Sn} \\
\mathrm{NbTi} \\
\mathrm{NbTi} \\
\mathrm{NbTi} \\
\mathrm{NbTi} \\
\mathrm{Nb}_{3} \mathrm{Sn} \\
\mathrm{NbTi}\end{array}$ \\
\hline
\end{tabular}

"Work performed under the auspices of the US Department of Energy by Lawrence Livermore National Laboratory under contract number W-7405ENG-48 and Princeton Plasma Physics Laboratory under contract number DE-AC02-76CH03073 


\section{B. Segmented CS Design}

The Segmented CS design is shown in Fig. 2 and coil parameters in Table II. All of the solenoid modules (CS, CSIU\&L, CS2U\&L) are pancake-wound with $\mathrm{Nb}_{3} \mathrm{Sn}$ superconductor, each with uniform current density. Coils PF2 and PF7, relieved by the end-coils, demand less current than in the Detailed Design configuration and are therefore designed with $\mathrm{NbTi}$ superconductor. The main CS module is about $9.5 \mathrm{~m}$ long, and gaps between the CS module and the end-coils are minimal. Leads must exit the solenoid modules radially and joints are located in the bore.

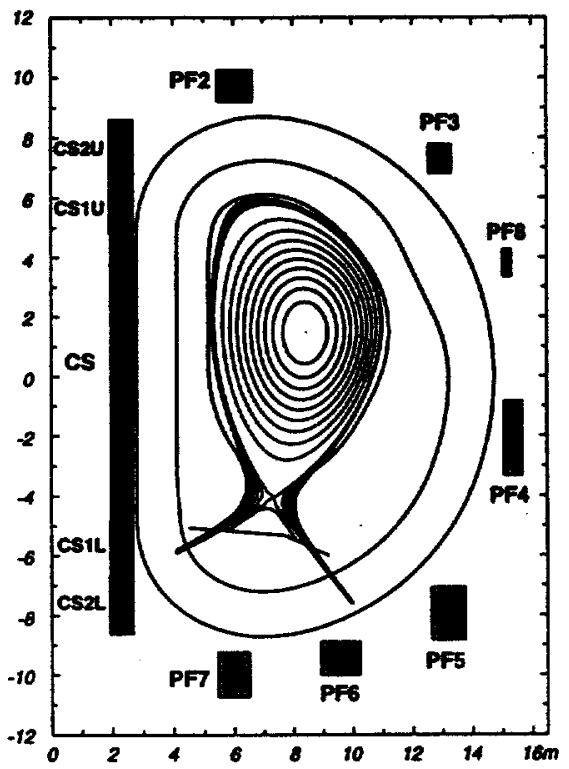

Fig. 2. PF coil arrangement for the Segmented CS Configuration.

Table II. PF coil specifications for the Segmented CS Configuration.

\begin{tabular}{|c|c|c|c|c|c|c|}
\hline $\begin{array}{c}\text { coil } \\
\text { name }\end{array}$ & $\begin{array}{c}\boldsymbol{R}_{\mathrm{c}} \\
\mathbf{m m}\end{array}$ & $\underset{\mathbf{m i n}}{Z_{c}}$ & $\begin{array}{l}\Delta R_{\mathrm{c}} \\
\mathrm{mm}\end{array}$ & $\frac{\Delta z_{r}}{\mathrm{~mm}}$ & $\begin{array}{l}N I_{\text {cap }} \\
\text { MAt }\end{array}$ & $\begin{array}{c}\text { cond } \\
\text { type }\end{array}$ \\
\hline $\begin{array}{l}\text { CS0 } \\
\text { PF2 } \\
\text { PF3 } \\
\text { PF4 } \\
\text { PF5 } \\
\text { PF6 } \\
\text { PF7 } \\
\text { PF8 } \\
\text { CSIU } \\
\text { CSIL } \\
\text { CS2U } \\
\text { CS2L }\end{array}$ & $\begin{array}{r}2321 \\
6049 \\
12947 \\
15364 \\
13198 \\
9580 \\
5990 \\
15177 \\
2306 \\
2306 \\
2300 \\
2300\end{array}$ & $\begin{array}{r}0 \\
9738 \\
7277 \\
-2090 \\
-7943 \\
-9452 \\
-9981 \\
3809 \\
5672 \\
-5672 \\
7616 \\
-7616\end{array}$ & $\begin{array}{r}728 \\
1175 \\
766 \\
593 \\
1115 \\
1295 \\
1057 \\
273 \\
759 \\
759 \\
770 \\
770\end{array}$ & $\begin{array}{r}9455 \\
1026 \\
963 \\
2485 \\
1768 \\
1122 \\
1505 \\
915 \\
1750 \\
1750 \\
1998 \\
1998\end{array}$ & $\begin{array}{r}108.9 \\
13.6 \\
9.4 \\
17.6 \\
16.9 \\
13.5 \\
18.3 \\
3.5 \\
17.6 \\
17.6 \\
21.4 \\
21.4\end{array}$ & $\begin{array}{l}\mathrm{Nb}_{3} \mathrm{Sn} \\
\mathrm{NbTi} \\
\mathrm{NbTi} \\
\mathrm{NbTi} \\
\mathrm{NbTi} \\
\mathrm{NbTi} \\
\mathrm{NbTi} \\
\mathrm{NbTi} \\
\mathrm{Nb}_{3} \mathrm{Sn} \\
\mathrm{Nb}_{3} \mathrm{Sn} \\
\mathrm{Nb}_{3} \mathrm{Sn} \\
\mathrm{Nb}_{3} \mathrm{Sn}\end{array}$ \\
\hline
\end{tabular}

\section{Hybrid CS Design}

The Hybrid CS design features a $9.5 \mathrm{~m}$ central solenoid module, but it is layer-wound as in the baseline design and is therefore radially graded. Gaps of about $1.5 \mathrm{~m}$ high are provided between the CSM coil and the end-coils for the CSM leads. Although the layer-wound and radially graded coil produces more flux than the CS module of the segmented design, the gaps result in a loss of flux production. The end-coils (CSU and CSL) are pancake-wound.

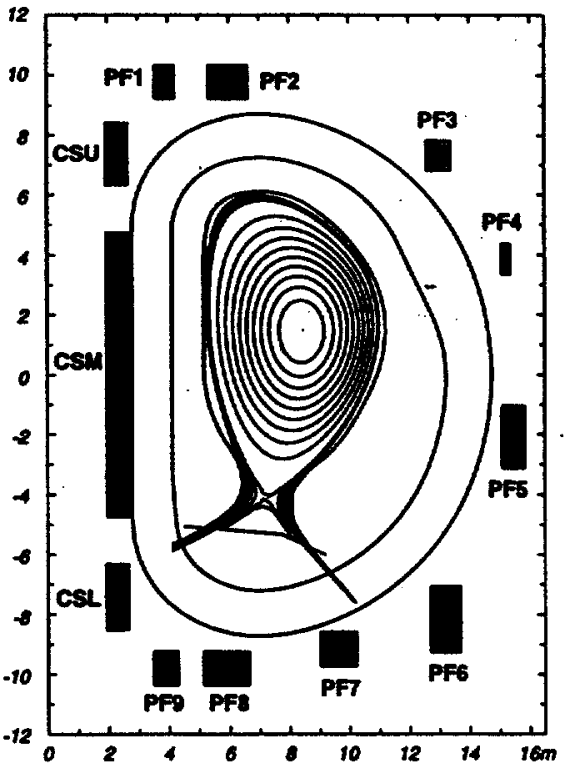

Fig. 3. PF coil arrangement for the Hybrid CS Configuration.

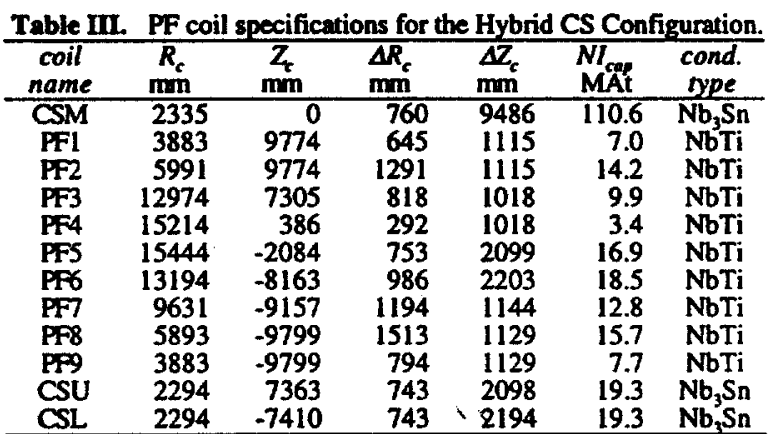

\section{THE ISSUES}

Vertically segmenting the ITER central solenoid offers improved plasma shape conformity over the scenario and enables higher upper triangularity, but results in poloidal flux crossing the straight portion of the TF coil inner leg which increases out-of-plane loads in this region. Segmentation also introduces gaps or inhibits radial grading in the CS which reduces poloidal flux consumption. Reducing the vertical extent of the CS coil, however, requires less compensation currents from the PF coils. This enables all of the PF coils to be designed with $\mathrm{NbTi}$ superconductor which is a significant cost savings over $\mathrm{Nb}_{3} \mathrm{Sn}$ conductor.

\section{REFERENCE SCENARIO PERFORMANCE}

The assessment of performance aspects were conducted with the Corsica [5] tokamak modeling code, particularly its freeboundary equilibrium solver and coil diagnostics modules.

\section{A. Requirements}

The 21 MA ignited mode of operation is the design basis for the ITER PF system. This operating mode is characterized by 
a set of nominal plasma parameters, and associated ranges of parameters which indirectly determine the cross-sectional size of the poloidal field coils. With the coils established for this operating mode, the system is subsequently characterized for other operating modes.

Requirements on the poloidal field system include shape tolerances which are applicable during the power-producing portion of the scenario, from the start of the current flattop state through the end-of-burn state. These tolerances are:

1. maintain the separatrix (and strike-points) in the divertor channels to within $\pm 100 \mathrm{~mm}$ of their reference position.

2. maintain the outer edge of the plasma in the region facing an ion-cyclotron heating (ICH) antenna to within $\$ 50 \mathrm{~mm}$ of its nominal position (withour exceeding a maximum radius of $10960 \mathrm{~mm}$ ), and

3. maintain a vacuum gap between the first-wall and the plasma scrape-off-layer (SOL) envelope of no less than $100 \mathrm{~mm}$.

The SOL envelope is defined as the flux surface passing through a point $50 \mathrm{~mm}$ outboard of the plasma edge. The tolerances listed above are static requirements, excursions beyond these values are allowable during transient control of disturbances.

The PF system is required to produce 1000 s burn duration (about $80 \mathrm{~Wb}$ of burn flux capability) for the $21 \mathrm{MA}$ reference scenario, within the current and field limits of the CS.

\section{B. Operational Flexibility}

The important plasma parameters are beta and internal inductance. The poloidal beta corresponding to $1500 \mathrm{MW}$ plasma power is:

$$
\beta_{p} \equiv \frac{4 V\langle p\rangle}{\mu_{0} R_{0} I_{p}^{2}}=0.9
$$

where $V$ is the plasma volume, $p$ the kinetic pressure, $R_{0}$ is the geometric mean radius (major radius), $I_{p}$ is the toroidal current and $\mu_{0}$ the permeability of free-space. The symbol pair ( ) denote a volume average over the plasma. The normalized internal inductance is defined as:

$$
\ell_{i} \equiv \frac{\left\langle B_{p}^{2}\right\rangle}{\mu_{0}^{2} R_{0} I_{p}^{2}}=0.9
$$

where $B_{p}$ is the poloidal magnetic field. Operational flexibility is expressed with ranges in beta and internal inductance: $0.7 \leq \beta_{p} \leq 1.2$, and $0.7 \leq \ell_{i} \leq 1.1$, where the beta range is applicable over the burn phase ( $\beta_{p}=0.1$ at the SOF state).

\section{Flux States}

Flux states are established either by coil technology limits, e.g., the end-of-burn (EOB) state occurs when the CS reaches a peak field of $12.75 \mathrm{~T}$, or by inductive and resistive flux consumption during the ramp-up, which set the start-of-flattop (SOF) and start-of-burn (SOB) states. Resistive flux consumption is estimated with Ejima scaling [6]:

$$
\Delta \Psi_{\text {resistive }} \approx C_{E} \mu_{0} R_{0} I_{p}
$$

with a coefficient of $C_{E}=0.45$ which establishes the flux linkage at the start-of-flattop state. Resistive consumption during the heating phase $(10 \mathrm{~Wb})$ is based on a loop voltage of $0.2 \mathrm{~V}$ over a $50 \mathrm{~s}$ heating period.

\section{Shape Conformity Results}

Fig. 4 shows the plasma boundaries over the full $\beta_{p}-\ell_{i}$ range of the $21 \mathrm{MA}$ scenario at the three fiducial flux states. Shape deviations are summarized in Table IV.
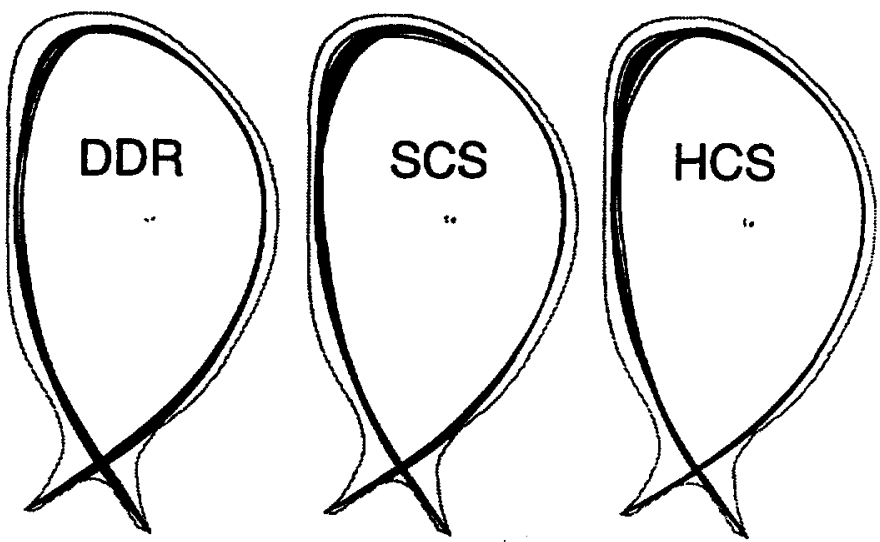

Fig. 4. Plasma boundary overlays at the SOF, SOB and EOB flux-states over the full range of operational space for the 21 MA scenario from the baseline (DDR) and the two altemate coil sets (SCS and HCS).

Table IV. Average maximum separatrix deviations $(\mathrm{mm})$ in the inboard divertor channel (\#1), outboard divertor channel (\#2) and ICH antenna region (\#3) over the full range of operational space for the 21 MA scenario from the baseline (DDR) and the two altemate coil sets (SCS and HCS).

\begin{tabular}{c|ccc|ccc|rrr}
\hline & \multicolumn{3}{|c|}{ DDR } & \multicolumn{3}{c|}{ SCS } & \multicolumn{3}{|c}{ HCS } \\
region & $\# 1$ & $\# 2$ & $\# 3$ & $\# 1$ & $\# 2$ & $\# 3$ & $\# 1$ & $\# 2$ & $\# 3$ \\
\hline SOF & 38 & 73 & 34 & 28 & 58 & 40 & 18 & 28 & 16 \\
SOB & 44 & 36 & 13 & 15 & 21 & 11 & 7 & 9 & 8 \\
EOB & 50 & 28 & 11 & 45 & 34 & 15 & 19 & 26 & 11 \\
\hline
\end{tabular}

\section{E. Plasma Parameters}

The burn flux capability: $\Delta \Psi_{\text {burn }}$, MHD safety factor: $q_{95}$, upper triangularity: $\delta_{U 95}$, and average triangularity: $\delta_{95}$, during the current flattop portion of the nominal $21 \mathrm{MA}$ scenario are presented in Table $\mathrm{V}$.

Table V. Plasma parameters for the reference 21 MA scenario with nominal plasma parameters for the three coil set options.

\begin{tabular}{clrrr} 
& & DDR & SCS & HCS \\
\hline$\Delta \Psi_{\text {burn }}$ & (Wb) & 80.6 & 77.8 & 79.4 \\
$q_{95}$ & SOF & 2.83 & 3.00 & 2.94 \\
$q_{95}$ & SOB & 2.94 & 3.07 & 3.07 \\
$q_{95}$ & EOB & 3.04 & 3.04 & 3.08 \\
$\delta_{U 95}$ & burn & $\mathbf{0 . 2 5}$ & $\mathbf{0 . 2 8}$ & 0.30 \\
$\delta_{Q S}$ & bum & $\mathbf{0 . 2 3}$ & 0.24 & 0.25 \\
\hline
\end{tabular}




\section{F. Coil Current Demands}

Peak coil current demands over the operational space of the 21 MA scenario are compared in Table VI for the three coils sets.

Table V. Coil current demands over the full operational space of the 21 MA scenario from the three coil sets. (PF2 from initial magnetization state.)

\begin{tabular}{lrr|rl} 
& DDR & SCS & HCS & \\
\hline CS & 138.6 & 109.1 & 111.1 & CSM \\
PF2 & 16.0 & 12.1 & 7.0 & PF1 \\
PF3 & 7.5 & 7.8 & 14.2 & PF2 \\
PF8 & - & - & 9.4 & PF3 \\
PF4 & 17.6 & 17.2 & - & PF4 \\
PF5 & 17.6 & 15.8 & 14.4 & PF5 \\
PF6 & 9.9 & 13.5 & 18.0 & PF6 \\
PF7 & 27.3 & 13.2 & 10.1 & PF7 \\
CS1U & - & 15.3 & 15.7 & PF8 \\
CS1L & - & 16.8 & 7.7 & PF9 \\
CS2U & - & 21.4 & 19.3 & CSU \\
CS2L & - & 21.1 & 19.3 & CSL \\
\hline
\end{tabular}

\section{G. Out-of-Plane Loads}

Fig. 5 is shows a comparison of the out-of-plane loads on the TF coil winding pack at the start-of-flattop state for the baseline and two alternate coil sets.

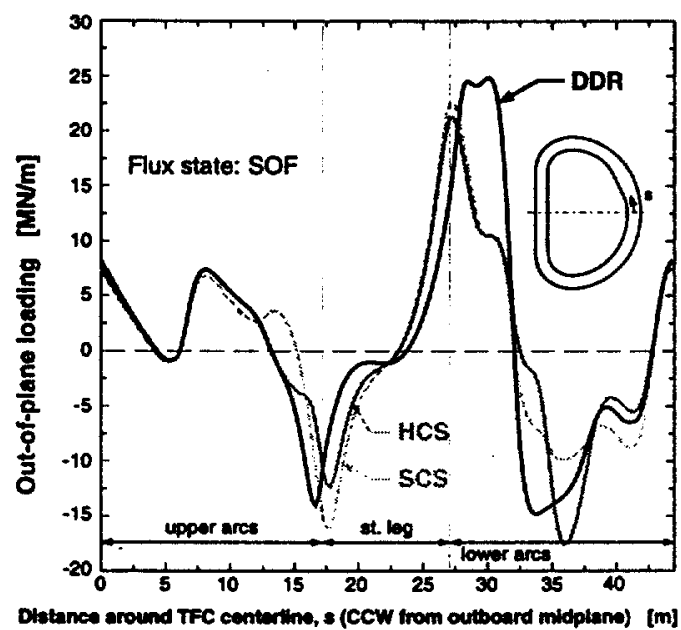

Fig. 5. Out-of-plane loads on the TF coil winding packs at the SOF state.

It is interesting that the peak loading, occurring near the lower divertor coils ( $24 \leq s \leq 30 \mathrm{~m}$ ), is greatest for the Detailed Design configuration, but in the straight-leg region the loading is greater for both the Segmented and Hybrid CS options. The out-of-plane loads in the straight section of the TF coil get transmitted to the CS or CSM coils producing a torsional stress in the solenoid winding. Some of this loading is taken up by the insulation bond around the conductors, and in the case of the Hybrid CS in particular, the insulation bond stress exceeds allowable values by almost a factor-of-two.

\section{H. 21 MA Scenario Performance Summary}

Fig. 4 and Table IV clearly show the benefit of a shorter central solenoid. Although all three coil sets satisfy the design requirements, the Segmented and Hybrid CS designs offer significant reduction in shape deviations in the divertor channels and antenna region. The alternate coil sets also improve the MHD safety factor and triangularity (Table $V$ ). There is some loss in poloidal flux production in the altemate designs, but with an estimated loop voltage of $0.07 \mathrm{~V}$ or less during the burn phase, all designs will provide more than $1000 \mathrm{~s}$ of burn duration.

\section{FINAL DESIGN CONFIGURATION}

The high-field joint technology demanded by the Segmented CS design, and the excessive insulation bond stress in the CSM module in the Hybrid CS design resulted in abandonment of these two alternate coil configurations. The configuration chosen for the ITER Final Design [7] is essentially that of the Detailed Design Report, except the primary elongation coils (PF2 and PF7 in Fig. 1) have been split into two coils to enable their construction with $\mathrm{NbTi}$ superconductor. This offers some cost savings, although little improvement in performance.

\section{SUMMARY}

Both the Hybrid CS and Segmented CS designs offer significant reductions in plasma shape deviations, and both offer some cost savings. The Segmented CS design requires $13 \mathrm{~T}$ superconducting joint technology which is beyond the scope of the EDA, but the Hybrid concept may be feasible if insulation $R \& D$ is successful.

\section{ACKNOWLEDGMENTS}

The authors wish to thank the ITER Joint Central Team in Naka, particularly M. Huguet, R. J. Thome, P-L. Mondino and $\mathrm{Y}$. Gribov for providing the motivation and guidance for this work. Members of the ITER US Home Team from GA, LLNL, MIT and PPPL were instrumental in this study.

\section{REFERENCES}

[1] P-L. Mondino, "ITER plasma shaping and control: a comparison of alternative magnetic configurations", these proceedings.

[2] P. Heitzenroeder, et al., "Engineering overview of the ITER hybrid central solenoid", these proceedings.

[3] Segmentation of the ITER Central Solenoid, Design Study by the United States Home Team, December 1996

[4] ITER Detailed Design Report, 12 November 1996

[5] 3. A. Crotinger, et al., "Corsica: A comprehensive simulation of toroidal magnetic fusion devices", LLNL Report UCRL-ID-126284, March 21, 1997

[6] S. Ejima, et al., "Volt-second analysis and consumption in Doublet III plasmas", Nuc. Fus., 22, 1313 (1982).

[7] R. J. Thome and P. Barabaschi, "Recent progress on the International Thermonuclear Experimental Reactor (ITER) magnet systems", these proceedings. 


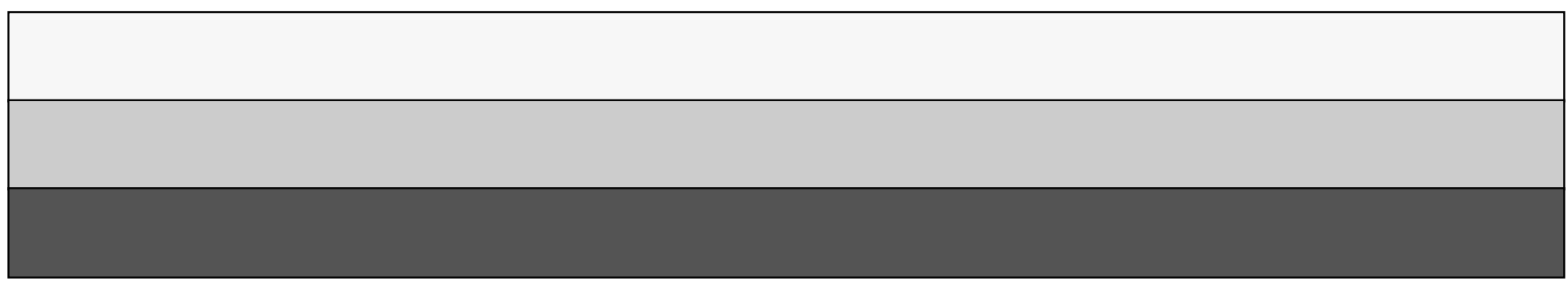

